\title{
Erratum to: Infinite motion and 2-distinguishability of graphs and groups
}

\author{
Wilfried Imrich • Simon M. Smith • \\ Thomas W. Tucker • Mark E. Watkins
}

Published online: 19 July 2014

(C) Springer Science+Business Media New York 2014

\section{Erratum to: J Algebr Comb DOI 10.1007/s10801-014-0529-2}

In Example 4.3 (iv), lines 2 and 4, the original correct expressions are $g=b^{n_{0}} c_{n_{1}} \cdots c_{n_{\ell}}$ and $g=c_{n_{1}} \cdots c_{n_{\ell}}$, respectively.

The online version of the original article can be found under doi:10.1007/s10801-014-0529-2.

W. Imrich

Montanuniversität Leoben, 8700 Leoben, Austria

e-mail: imrich@unileoben.ac.at

S. M. Smith $(\varangle)$

Department of Mathematics, NYC College of Technology, City University of New York, New York, NY, USA

e-mail: sismith@citytech.cuny.edu

T. W. Tucker

Department of Mathematics, Colgate University, Hamilton, NY, USA

e-mail: ttucker@colgate.edu

M. E. Watkins

Department of Mathematics, Syracuse University, Syracuse, NY, USA

e-mail: mewatkin@syr.edu 